\title{
A POLITICA, O PODER E O DIREITO: REFLEXÕES E FRAGMENTOS AO PENSAMENTO DE LUHMANN
}

\section{Luciano Braz Silva ${ }^{1}$}

\section{Resumo}

Analisar os aspectos do poder, como formas de dominação e a sua relação com a política e o direito, constitui objeto desse artigo. Neste sentido, nosso artigo antecipa suas reflexões suscitando de antemão algumas questões, tais como: haveria algum sentido para pensarmos uma coexistência entre o poder, a política e o direito? A existência/permanência do direito estaria comprometida divorciada duma coexistência do poder? Tomando como referencial teórico a obra de Niklas Luhmann nosso artigo direcionará suas análises a concepção sistêmica do direito e da política atrelando ao conceito de poder abordado no pensamento de Luhmann.

Palavras-chave: Poder. Política. Direito. Sistema. Comunicação.

\section{INTRODUÇÃO}

O presente artigo traz para seu campo de reflexões três temas que embrionariamente estão atrelados a filosofia do direito, a saber, o poder, a política e o direito. Entendemos que não basta tão somente uma nova releitura crítica a esses temas que há muito tempo já foram objeto de análises críticas por renomados filósofos do direito tanto no plano internacional como na filosofia do direito brasileira. Evidentemente, o presente artigo não pretende esgotar os tópicos aqui destacados, aliás, guardadas as devidas proporções, artigo nenhum possui condições para esgotar seriamente qualquer temática que se proponha ser abordada no aspecto científico. De fato,

\footnotetext{
${ }^{1}$ Doutorando em Direito pela Pontifícia Universidade Católica de São Paulo - com bolsa CNPq - sob orientação do Prof. Dr. Tercio Sampaio Ferraz Jr. Diretor do Diretório Acadêmico do Curso de Direito do UNIVEM 2008. Integrante do Grupo de Pesquisa Científicas BIO-ÉTICA - coordenado pelo Prof. Dr. Oswaldo Giacoia Jr, nas dependências do UNIVEM. Possui cadastro no Grupo de pesquisa - Processos político-sociais e exclusão - Unesp-Marília. Pesquisador com cadastro junto ao CONPEDI Conselho Nacional de Pesquisa e Pós-Graduação em Direito - desde 2009. E-mail: brazadvogadoluciano@gmail.com
} 
os temas aqui abordados - dada a relevância teórica e crítica para a filosofia do direito - constituem tópicos para serem abordados em dissertações ou teses doutoramento ao que certamente o resultado seria outro que não este que aqui se apresenta.

Nosso artigo pretende oferecer ao leitor não uma nova perspectiva para os tópicos que aqui serão abordados visto que esses tópicos não são inaugurados neste artigo, pelo contrário, há uma vasta obra literária jusfilosófica que se debruça sobre os temas, tanto, internacional como nacional, em destaque Marcelo Neves, Willis Santiago Guerra Filho e Tercio Sampaio Ferraz Jr. Então qual seria a proposta do nosso artigo? Não poderia ser outra que não a de tentar estabelecer uma perspectiva teleológica - elaborada sob a ótica da filosofia do direito que abrangerá o conteúdo de cada um dos termos aqui abordados, a saber, o poder, a política e o direito. A ordem dos tópicos não surgiu por acaso. Aqui pedimos vênia para discordar daqueles que pensam duma forma contrária a nossa, porém, acreditamos que toda ciência é secundária aos fenômenos. Não existiria ciência sem a ocorrência de um fenômeno que a antevê, seja no campo das exatas (física), das humanas (sociais aplicada), biológicas e etc. O conteúdo da ciência se debruça sobre algum objeto especifico e sobre esse objeto a ciência produz conhecimento. O homem por natureza é um ser que se relaciona com o mundo e com os demais sujeitos, ao se relacionar com algo ou com alguém, o mesmo o faz por duas razões: carência (necessidades) ou afeto. No campo da carência que visa suprir as necessidades físicas (alimentação, vestuário, proteção, moradia) estão afetas aos campos da ciências sociais aplicadas (direito, antropologia, psicologia, teologia etc) e da exata (economia, engenharia) e no campo do afeto temos a ciência da arte ou das artes. Portanto, neste relacionar o homem produz intercâmbios, trocas, negociações, mediações com aqueles que ajudam circunscrever seu ambiente. Aqui, encontramos a célula matriz das relações de poder que visa prover a manutenção da vida. A primeira relação que o filho estabelece com a sua mãe não é permeada pelo afeto, pelo parentesco sanguíneo ou por uma questão religiosa, antes sim, o mesmo ao se relacionar com sua mãe só o faz com o sentido de suprir determinada carência, a saber, a manutenção da sua vida. Aqui não há nenhuma comunicação (por parte da criança), mas somente, interesse pessoal (necessidade). A criança estabelece uma relação de poder com sua mãe, ou melhor, se apodera da sua mãe, a possui como se a mesma fosse propriedade sua e, nesse sentido, temos aqui uma relação de posse. Isso não difere das relações políticas, sociais-econômicas e religiosas, a posse, a sede, e o desejo de poder (dominação) subjaz as relações. Portanto, o poder é algo se destaca e assume relevância em primeira ordem nas relações que ocorrem nas mais variadas espécies/formas de relações entre sujeitos, grupos e comunidades. Uma generalização do poder demandaria variadas análises sobre a própria essência do poder com o fim de tentar extrair dessas análise algum sentido. O poder seria algo, um objeto passível de apropriação por alguém ou por um grupo? O poder seria uma faculdade/ideologia capaz de produzir obediência? O poder poderia ser descrito como instrumento de exercício da soberania/império? 
Considerações então observadas, em que sentido o direito poderia ser destacado como uma espécie de poder? A comunicação seria um poder? Sendo um poder, poderíamos dizer que de fato há uma comunicação? Em que medida o direito pode conviver com o poder? E ainda, o poder deve ser obedecido, porquê? Todas essas perguntas não tem como causa, em primeira análise, indagar sobre uma suposta legitimidade do poder, aqui destaca-se a conotação em vista do que, deveras, algo deve ser obedecido, ou seja, sua finalidade.

Em segundo plano, nosso artigo direciona suas atenções para o campo da política analisando-a como um componente que permeia a sociedade, algo que se assemelha como a derme do corpo que a envolve como uma membrana. Aqui, não se trata de analisá-la num aspecto de uma mera relação, algo destituído de uma certa racionalidade técnica ou cálculo de demandas. A política será observada como um sistema próprio que possui uma funcionalidade específica atrelada a uma finalidade. Como um sistema fechado em si mesmo a política, igualmente o direito, é impulsionada pelas contingencias suscitadas no seu entorno. A pergunta que o presente artigo elabora a acerca da função do direito traz embutida uma questão de fundo voltada ao sistema da sociedade, a preocupação de fundo desta pergunta busca resolver/solucionar patologias do sistema social como um todo. Aqui, a ciência do direito se depara com uma tarefa muito árdua que lida especificamente com aquelas problemáticas oriundas de afirmações, consciência e modo de ser dos indivíduos, suas expectativas e segurança. A estabilização de expectativas demanda, como veremos, uma seguridade que irá conferir aos indivíduos condições para enfrentar/lidar com a desordem, abalos e demais patologias da vida social/cotidiana como um todo. Uma das observações que o artigo traz para seu corpo, lida especificamente com os pressupostos da função da norma a qual nos orienta a respeito da função própria do direito. Com isso, procuraremos observar, e já caminhando para a parte final do nosso artigo, em qual medida a aplicação do direito depende da política para tanto, a recíproca também é verdadeira, vez que analisaremos qual a razão pela qual a política deve recorrer ao direito como condição para se obter o devido acesso ao poder politicamente concentrado. Não restrita tão somente ao ponto de vista político, mas, sobretudo, do ponto de vista da moral, trata-se da questão de saber se uma ação pretendida/exigida pode ser imposta mediante coação.

O fundamental para uma introdução como a que aqui se pretende é poder suscitar inquietações argumentativas que tendem, de certa forma, elucidar possibilidades duma possível reprodução das funções estruturais dos sistemas-social e dos ( $\mathrm{sub}$ ) sistemas que se reproduzem e se integram (o direito, a economia, a religião, a política etc.). Analisar esse funcionalismo estrutural que interliga o Poder, a Política e o Direito, aflora inquietação axiológicas, axiomáticas e ontológicas quanto a função própria das estruturas dos sistemas e a suas respectivas funcionalidades, no sentido de dar um passo, ou, alguns passos a mais para além da técnica de decomposição, modo de identificação (interpretação/analise hermenêutica), manutenção, variáveis teoréticas como um todo. 


\section{O PODER}

Desde os períodos mais remotos muitos esforços foram empregados pelos intelectuais das ciências humanas afim de descrever ou conceituar empiricamente o poder. A relevância do assunto deveu-se, e ainda nos parece relevante, considerando a realidade contumaz do poder que se revela como sendo uma prática social de diferentes formas que se articulam de maneiras variadas a pretexto da sua própria manutenção. Com isso, sua fenomenologia nos pareceu constituir tarefa para uma análise impreterível, uma tarefa incumbida àqueles que lindam com as questões ligadas a teoria do direito, a ciência política, a filosofia política e, sobretudo, com a filosofia do direito. Sabe-se que na tentativa de descrever e conceituar onto/geneologicamente o poder chegou-se a variadas contradições que nos causou mais repercussões do que deveras soluções práticas reais. Destarte, a realidade nos mostra que o debruçar sobre uma teoria do poder não pode se limitar/reduzir a uma interpretação descritiva ou a uma possível análise essencial do poder como condição para se obter um resultado pretendido, ou, ainda quem sabe, uma pré-consciência-técnica que nos levaria acertar um passant ou um garfos². Dada a relevância do poder qualquer análise, que se pretenda respeitável, deverá transcender pontos isolados ou perspectivas unilaterais, ou melhor, deverá buscar conceitos mais abrangentes circunscritos em outros contextos de tal modo a possibilitar comparações e investigações conexas com outros campos.

Niklas Luhmann (1985, p. 4), em sua obra Poder (Macht) nos propõe algumas questões embrionários fronte a temática proposta. As questões suscitadas pelo teórico arrostam indagações que lidam com os fundamentos, ou possíveis fundamentos, que procuraram examinar o poder. Daí surge, inicialmente, a possibilidade de investigar tais construções conceituais, de forma imanente, quanto à sua coerência teórica e conclusiva, considerando, todavia, verificações variadas de contingências. Segue Luhmann.

É possível perguntar, no caso de o poder dever ser um processo causal, pelos fundamentos não-causais da causalidade; no caso de ser uma troca, pelos fundamentos não permutáveis da troca; no caso de ser um jogo entre adversários, pelos fundamentos não-jogáveis do jogo. Esta técnica de questionamento permite chegar à sociedade como condição de possibilidade do poder. Ela busca uma teoria do poder através de uma teoria da sociedade.

É certo que nosso artigo não comporta uma exposição unívoca um tanto quanto pretenciosa. Toda cautela necessária nos orienta subtrair os equívocos a não nos arriscar a enfadonha e cinzenta compreensão duma suposta genealogia ou uma antologia do poder. Pensar uma teoria geral do poder, algo que poderia ser descrito a partir das premissas que constituem sua natureza/característica (s), ou sua/uma essência que nos possibilitaria expor e definir suas características universais, certamente, seria uma tarefa de soma zero. A razão disso nos parece muito evidente, embora haja uma descontinuidade com aquilo que normalmente se entende por teoria, ainda

\footnotetext{
${ }^{2}$ Jogadas de xadrez. A tática consiste em pensar nas mais diversas possibilidades de movimentação das peças em uma determinada, ou em uma sequência de jogadas, visando sempre, seja em qual for a tática usada, capturar o rei adversário e finalizar com o jogo.
} 
assim, toda teoria tem revelado uma característica de temporalidade ao que por conseguinte revelou também uma certa descontinuidade dado suas limitações e desenvolvimento acidental. Contudo, não podemos negar às análises genealógicas do poder aquilo que elas poderiam nos informar quanto a produção de relevantes deslocamentos com relação à ciência política que limita o Estado o fundamental de sua investigação sobre o poder. O fenômeno do poder, para Sampaio Ferraz (2009, p. 35), trata-se de algo irredutível. Para o jus-filósofo é possível apontar o que há de mais central e oculto em seu processo, mas, "dizer-lhe o núcleo essencial é tarefa que esbarra numa sensação de multiplicidade, individual e socialmente dispersa, que nos assalta a cada passo como uma descoberta adolescente”. É possível sim diagnosticarmos permeações do poder em múltiplos horizontes tais como: na economia, na religião, na política, na cultura, no direito, no campo do discurso, na persuasão, na violência, na resistência e até mesmo nas situações de fraqueza e desamparo. Consoante análise, uma questão embrionária nos salta aos olhos: por onde devemos principiar nossa análise sobre o poder?

\section{A comunicação: sua relação com o poder}

Analisar e compreender a/uma teoria da sociedade, com seus principais elementos tomados a partir do século XIX, nos faz constatar duas perspectivas que se observam. Por um lado temos a teoria da diferenciação social constituída/erigida por estratos e por subsistemas funcionais, e, por outro lado, temos a teoria da evolução sociocultural. Niklas Luhmann entende que ambos pontos de partida se reuniram na tese de que a evolução sociocultural desemboca numa diferenciação crescente. Para o teórico, algumas questões ligadas a comunicação, por exemplo, questões de motivações para aceitar e seguir comunicações não foram esclarecidas por esse tipo de abordagem. Essas abordagens, conclui Luhmann (1985, p. 5),

Percebeu-se que as questões elementares/ essenciais da comunicação e da motivação não haviam sido ignoradas por princípio da teoria da sociedade, contudo, não se atribui o mesmo grau de equivalência/ importância dos conceitos principais. As consequências não foram as esperadas; se há que deverás existir alguma boa esperança para se alcançar. $\mathrm{O}$ que se sabe, na verdade, até certa medida, houve um pretenso interesse humanitário e paralelamente uma humanidade perdida que culminou num protesto desigual. Neste sentido, a formulação de uma teoria geral de comunicação simbólica mostrou-se como uma possibilidade/instrumento para solucionar, senão atenuar, até certa medida problemas de diferenciação social. Assim, uma teoria geral da comunicação deveria relacionar com as sentenças, mecanismos e fases da evolução sociocultural com fim de suprir carências prejudiciais (LUHMANN,1985, p. 5). Deve-se evitar, contudo, a ideia de se recorrer a um macrosujeito pensado na perspectiva da filosofia transcendental. A comunicação, nas observações de Luhmann, trata-se duma premissa elementar à constituição dos sistemas sociais. Mediante a comunicação constata-se o fato 
dos múltiplos processos de seleção que se determinam mutuamente por antecipação ou por reação. Nesse sentido, compreende-se que as necessidades de um acordo seletivo antecedem e, por derradeiro, constituem a formação da sociedade; por outro lado, tais necessidades só são experimentadas nos sistemas sociais. Logo, comunicação e compreensão não podem ser pensadas divorciadas uma da outra vez que a seletividade de uma mensagem deve ser pressuposta mediante ambas, daí a razão pela qual se erige um sistema próprio que contempla as contingências de ambas as partes, e, por conseguinte, também a escolha/recusa das ofertas de seleção apresentadas por via comunicativa (tomadas de sim e não).

A comunicação, todavia, deve ser mediada por elementos complementares da linguagem então mantidos num processo permeados por códigos de símbolos generalizados que regula a transmissão de resultados seletivos. Na medida em que os meios de comunicação sugerem a adoção de resultados seletivos externos, os meios de comunicação assumem a função motivadora e concomitantemente assegura a compreensibilidade intersubjetiva dos envolvidos nas tomadas de escolha. Os símbolos elaborados remontam as contingencias subjacentes nos mais variados contextos. Tais contingências não são estranhas à compreensão dos envolvidos (concernidos), muito pelo contrário, as contingências configura-se como um local de estoque, um arcabouço, um depositório perene sempre acessível aos sujeitos, vez que daí seleção e motivação são tomadas dos símbolos que ocupam tal repertório, ao que por conseguinte, passam assumir a função de mediadores para ambos os lados. Rocher (1976, p. 18-21) citando Parsons, destaca que nesses moldes, compreender uma ação humana, significa dizer compreender também as razões de ordem de motivação e inspiração provenientes dos significados que o ator descobre no mundo exterior, significados esses determinantes aos quais responde. Ora, a ação social passa ser interpretada a partir da subjetividade do ator, isto é, a partir da percepção que lhe é afeta oriunda do seu meio ambiente, dos sentimentos que o animam, das concepções que lhes são próprias, das motivações que o impulsionam e das reações decorrentes da sua própria ação. Cabe salientarmos de forma clara que ator ou sujeito que aqui se menciona pode ser um indivíduo, mas também pode ser um grupo de pessoas, um partido político, uma sociedade regional ou global, ou uma civilização inteira. Esta determinação encerra uma série de pressupostos e implicações que valem também para uma teoria do poder.

No campo da ciência do direito aquilo que nos salta aos olhos como poder possui nítida relação com o termo/conceito domesticação atrelada a noção de soberania. Para Sampaio Ferraz (2009, p. 30) "o direito não conhece outro poder que não esse". Contudo, podemos descrever algumas situações que a primeira vista parece estarmos transitando no campo jurídico, porém, essas situações quando observadas em suas pormenores nuances revela algo de surpreendente, a saber, não se restringem a uma conotação fechada ao campo do direito. Por exemplo situações como estado de sítio, estado de necessidade e estado de exceção, mesmo que a priori externam um caráter jurídico, na verdade ocultam um fenômeno (o poder) que o direito não consegue capturar 
inteiramente. Quando nos referimos a expressão necessidade, de fato, tal expressão alude ao que especificamente estamos pretendendo dizer com tal expressão? Na expressão, estado de necessidade, aponta Sampaio Ferraz (2009, p. 30-31),

Não é uma noção jurídica. Estado de necessidade o é, mas a necessidade, à qual se faz referência, com toda sua força de fato, como algo que ninguém segura, parece justamente que estamos falando quando estamos falando de poder. E na noção de estado de necessidade, ou na noção de estado de sitio talvez se ache uma curiosa pista para nos mostrar que, na relação entre poder e direito, um não se reduz totalmente ao outro. $O$ modo usual pelo o qual o direito lida com o poder é um modo de jurisfação total. As noções jurídicas para lidar com o poder tentam reduzir o poder ao direito.

Situações extremas nas quais se denota uma certa antinomia do direito percebe-se algo estranho/contrário aquilo que se convencionou conceituar como direito. Aqui, entendo tratar-se duma situação que não devemos denominar como sendo uma outra face do direito, visto que, atendendo ao princípio da não contradição, uma coisa não pode não ser e ser ao mesmo tempo. Contudo, convém destacar que o poder, mormente, encontra-se ali, instado lado a lado com o direito, de modo que ao lidamos com esse tema/fenômeno (poder) o fazemos utilizando noções extraídas da ciência jurídica que lida com o conceito/definição de soberania, e assim chegamos a compreensão de que o poder não se trata especificamente de uma coisa passível ou não de ser captada, porém, o poder em si, exprime um fato, um fenômeno que realça uma relação simbólica que se diferencia em tempos e ocasiões e assim obsta qualquer pretensão de uma possível (sua) captação homogênea total. Sampaio Ferraz (2009, p.31) destacaque na relação entre o direito e o poder, de fato, o poder é visto como sendo um núcleo, mas que não se consegue ser totalmente captado pelo direito "subvertendo, por assim dizer, o próprio direito como poder domesticado". Daí surge para nós, pesquisadores do direito, uma questão nuclear no que se refere a relação entre direito e o poder, direito é poder, mas se contrapõe ao poder? Uma perspectiva a ser tomada, seria observar poder e direito como meios simbólicos de comunicação, percepção essa que nos possibilita observar o direito numa perspectiva orgânica do poder e do direito assentada num contexto comunicacional.

Luhmann (1985, p.8) destaca em primeiro passo os meios de inter-relação, como pressuposto mais importante, vez que para ele, os processos de comunicação dirigidos pelos meios inter-relacionam os parceiros, que "efetuam ambos operações seletivas próprias, tendo conhecimento simultâneo um do outro". Neste ponto Luhmann elucida aspectos que tratam diretamente daquilo que se entende por Alter e Ego. Meios de comunicação existem quando estamos diante de situações sociais que possibilitam (oferecem) escolhas para ambas as partes, situações determinantes a seletividade duplamente contingente, ou seja, o sujeito ao propor ou tomar uma escolha concomitantemente se divorcia daquela anterior. Temos aqui a função diretiva dos processos de transmissão das seleções, em sua seletividade do Alter para o Ego, a comunicação, influenciando, dirigi as seleções que permeiam as relações entre os parceiros.

Os meios combinam, pois, a comunidade das orientações e a não-identidade das seleções. 
Também o poder funciona como meio de comunicação somente sob esta condição básica. Ele ordena situações sociais com dupla seletividade. Por conseguinte, a seletividade do Alter deve ser distinguida da do Ego, dado que, com relação a elas, no caso do poder, dão-se problemas completamente diversos (LUHMANN, 1985, p. 8).

A noção de comunicação tomada na teoria luhmanniana assumi um caráter mais radical do que a mera ação comunicativa onde se verifica trocas de mensagens entre indivíduos ou grupos. A teoria de Luhmann assume um aspecto mais radical onde a comunicação assume uma estrutura de comportamento que envolve o Alter e o Ego (eu e outro-eu). Não se trata de um ato que advém do ego na direção do outro, nem do Alter na direção do Ego, antes sim, temos aqui um complexo que os envolve. Por conseguinte, a própria concepção de sociedade, descrita na teoria de Luhmann (2010, p.35-37), é tomada, também, num aspecto radical. Descrita numa perspectiva diferente daquela que há séculos vem sendo definida, a sociedade não é vista como sendo um conjunto de indivíduos, ou, mais radicalmente, a sociedade não é constituída por ser humano. A sociedade reflete situações comunicacionais, ou melhor, a comunicação constitui essência da sociedade e não o conjunto de atos de comunicação. Com isso, concebe-se a ideia de que a sociedade é uma estrutura (comunicacional) que possibilita a integração entre os indivíduos. Portanto, a razão da existência da sociedade não se dá por conta da relação dos indivíduos, mas o contrário sim.

Marcelo Neves (1994, p. 12) com seu brilhantismo intelectual destaca, num sentido filosófico, que o termo "simbólico" é tomado para indicar todos os mecanismos de intermediação entre sujeito e realidade. No sentido simbólico, entendemos, que o termo o homem é observado sobre dois aspectos, a saber, como ser pensante (vê e reflete) e, como ser que age (sente e age/comportamento). Aqui o sistema simbólico é tomado como um mecanismo para intermediação entre homem e realidade. A ação humana cognoscível aprende os axiomas e, por conseguinte, elabora juízos axiológicos. Essa ação diferida não se assemelha as reações orgânicas pautadas em estímulos exteriores diretas e imediatas. O homem, um ser estante na cultura, se reconhece e se desenvolve mediante a linguagem contextualizada pelo conjunto de símbolos que integra o sistema social. Porém, a relativa autonomia do sistema simbólico, como repertório/estrutura de significantes, fronte as relações sociais, possibilita, segundo o pensamento de Lévi-Strauss (1976, p. 33), a eficácia simbólica. Neste sentido, a estrutura social seria um sistema simbólico, não se confundindo com a própria realidade das relações sociais.

Em geral, supõe-se a sociedade como sendo um aglomerado de relações próprias não redutíveis às relações interindividuais, mas uma espécie de sistema macrossociológico de auto-referência no qual a função do poder se manifesta. A complexidade que envolve as situações comportamentais revela uma compulsão tendente a selecionar expectativas e possibilidades atualizáveis de interação. Destarte, dada a contingência e o estado de insegurança que permeia a comunicação, cria-se mecanismos que possam, de certa forma, garantir um certo grau de confiabilidade às expectativas em jogo, ofertando um certo grau de confiança fronte as possibilidade de 
desilusões. Esse mecanismo é composto de uma estrutura (conjunto de regras) e um repertório (conjunto de símbolos).

O poder em situações/organizações fortemente estruturadas migra/desloca-se para diferentes espaços onde ainda subsista algo de inseguro, um estado, um espírito ou sentimento de insegurança com relação às opções de ação postas, das quais outros - que ali estão - são dependentes. Esse seria então o pressuposto fundamental de todo poder naquilo que se refere à seleção do poderoso Alter, a insegurança. Deste modo, ele pode dada a escolha a ser feita pelo parceiro, gerar e, ao mesmo tempo, superar, nele, as inseguranças. O poder, neste sentido, gera e produz sua capacidade de transmissão mediante sua aptidão para influenciar a seleção de ações. Aqui, as possibilidade de escolhas do influenciado são reduzidas a uma somatória de cálculo zero. Este desiderato, aproxima-se muito daquilo que Luhmann identificou como caso-limite, que eu preferiria denominar de zonalimite. Seria a situação onde estaríamos diante duma coação e não, propriamente dito, duma ação mediada pelo poder. O que seria isso? A coação, diferentemente do poder, é mediada pelo uso da violência física que se dá pela substituição do agir próprio pelo agir, inatingível, de outros. Neste sentido, o poder perde aquilo que o constitui e que o caracteriza como tal, a saber, sua função de superar a dupla contingência, na medida que se aproxima e paulatinamente assume/assemelha-se o perfil da coação. $\mathrm{O}$ uso da coação reflete nítida falta de poder, implica, para quem a usa, assumir o peso da seleção e da decisão. A violência física, portanto, a coação põem-se outros corpos em movimento a fim de ocasionar, por exemplo, mudanças/alterações de suas posições no espaço (LUHMANN, 1985, p. 9).

O poder demanda uma neutralidade da vontade, neutralidade essa que seria sua causa. Aqui não estamos falando, ou propondo, exatamente uma ruptura da vontade do subalterno. Ora, pensar a existência de uma estrutura do poder e de uma decisão de poder antecipável tornaria sem sentido qualquer possibilidade de vontade do subalterno. A função do poder, para Luhmann (1985, p. 11) consiste, exatamente, na regulação da contingência sem perder de vista os resultados seletivos de Alter e Ego.

\section{A POLÍTICA}

Para os teóricos que adotam a teoria do sistema, uma reflexão séria que se propõe analisar o sistema jurídico e o sistema político devem partir da premissa que ambos sistemas se distinguem e se constituem. Ambos sistema são observados e identificados como sendo um subsistemas correlato ao sistema-sociedade que os diferenciando também se diferencia de ambos. A razão desta compreensão se evidencia quando compreendida mediante as premissas da autopoiese que propõe singularidade/individualidade histórica de todos os sistemas sociais. Outros teóricos não são adeptos a tal argumento, sustentam existir entre a política e o direito estreitos e 
evidentes nexos que os interligam um a um.

A teoria luhmanniana descreve e identifica o sistema jurídico formatado sob sistema da autopoiese operativamente enclausurado, assim, pressupõe que este sistema se distingue de todos os demais subsistemas que se interconectam com os diversos sistemas que integram as funções da sociedade. Portanto, um observador externo a este sistema deve, necessariamente, identificar essa distinção para ai sim observar e descrever de conformidade com os fatos. Contudo, em geral, mesmo que pareça que estamos diante duma evidencia, este conceito, para Luhmann (2003, p.291), apresenta dificuldades em um aspecto, a saber, precisamente na relação entre política e do direito. Luhmann identifica como marco inicial desta compreensão, que unifica a política e o direito por nexos intrínsecos, a Idade Moderna, em destaque o pensamento de Thomas Hobbes, Francisco Suáres, e Samuel Pufendorf. Para esses teóricos o sistema político e o sistema do direito, na verdade, constituem faces dum sistema unitário, em certa medida, isso deveu-se ao conceito simultâneo - político e jurídico - estão pensado sob égide da concepção do Estado. Essa concepção tomou como base o direito natural.

O desenvolvimento da comunidade europeia, deveu-se, sobretudo, a acentuação dos pressupostos jurídicos recorrentes na convivência social. Sem dúvida, essa convivência tomou como base ou fundamento o direito civil romano e a formulação dos seus princípios então fundamentados sobre o direito natural. $\mathrm{Na}$ consolidação política do Estado moderno o direito já estava presente e já era utilizado como tal. Nesta época já se falava num direito elaborado com as formalidade que lhes são próprias. Já se apontava/recorria institutos do direito previamente fixados/escritos. Em comum, já se encontrava espécies de direito, como por exemplo, o direito feudal, o direito da cidades, o direitos dos reis, o direito canônico e o direito civil profano.

Essa separação estendeu-se e configurou uma jurisdição correspondente diferenciada, donde, do ponto de vista jurídico, no século XVI, destaca Luhmann (2003, p. 292), não havia nenhum direito público e nem tampouco um conceito comum de direito (dominiu, império, iurisdicto) que poderia representar ou tratar especificamente de uma unidade (território) aderida há um poder territorial. De qualquer maneira não se imaginava separados a jurisdição (iurisdicto) e o império, já que isto, certamente, soaria como algo estranho para o pensamento daquela época, ou seja, um império em um território destituído do direito e uma jurisdição (iurisdictio) sem poder de imposição em si seria um argumento contraditório.

Questões socialmente relevantes pouco a pouco passaram a demandar observações jurídicas, ao que, por conseguinte, constatou-se respectivas relevâncias diferenciadas segundo sua natureza, segundo sua essência. $\mathrm{O}$ sistema social autodiferencia aglomerando-se ao sistema do direito, da ciência, da religião, da economia e da política, conforme a função que desempenhavam no sistema. Contudo, o sentido do sistema, ou de qualquer sistema, não seria outro que não de reduzir as complexidades existentes subjacentes as contingências. Essas questões de fundo assumiram certa relevância quando indagações jurídicas adentraram nos discursos que tinham 
como pauta o conceito de "potestas", ao que por conseguinte não seria diferente quando se buscou formular uma compreensão/conceito de soberania. Guerra Filho (2001, p. 186), destaca algumas funções essenciais que o sistema jurídico - como sistema funcional - propõe ao sistema global. Em teoria da ciência jurídica, Willis Santiago G. Filho, aponta que o sistema jurídico - em sua funcionalidade - possui a tarefa de reduzir a complexidade do ambiente e, por derradeiro, absorver as contingências do comportamento social ao garantir certa congruência entre as expectativas e comportamentos e a generalização desses comportamento e expectativas "pela imunização do perigo de decepcionarem". Para o jus-filósofo "daí ser o direito definido, na teoria sociológica luhmanniana, como 'generalização congruente de expectativas comportamentais', generalização essa que fornece 'uma imunização simbólica de expectativas contra outras possibilidades'” (Guerra Filho2001, p. 186).

Daqui decorre as primeiras concepções que mais tarde - paulatinamente - foram concebidas como sistema jurídico pátrio, ou sistema jurídico próprio que passou a distinguir as ordens jurídicas europeias, cada qual com a sua singularidade/particularidade regional de acordo com a evolução própria do seu direito, sua forma primária, suas práxis jurídicas e a erudição das cátedras de direito. Essa compreensão toma como ponto de partida razões que decorrem - de forma mais ou menos direta - evoluções políticas correspondentes. Mas, porém, pela dinâmica própria do direito e dada as especificidades que envolvem as problemáticas do direito excluem aquilo que se chamaria de uma "cópia" direta da representação duma ordem política no direito. Ora, é certo que decisões individuais são influenciadas por questões políticas.

$\mathrm{Na}$ Idade Moderna algumas questões atinentes ao direito, bem como, a administração da justiça assumiram relevância para o Estado. Essas inquietações, foram decorrentes da rápida e crescente complexidade e sensação de insegurança jurídica instalada. O Estado tomou como sua tarefa primordial promover a unificação do direito válido em seus territórios, bem como, dentre as suas primordiais tarefas organizar a administração da justiça. Essas incumbências pareceram - de sobremodo - serem urgentes para se chegar a um controle/administração central com o fim de consolidar a própria unidade do Estado. Neste contexto, começouse a formular uma compreensão de soberania e uma consolidação política do Estado/Território. Para Luhmann (2003, p. 293),

O conceito de soberania - o de poder soberano - encobria o jogo dos conceitos diferentes sobre o poder político: a noção de capacidade generalizada de que as ordens se obedeceriam, e a noção do poder jurídico que havia sido possível reconhecer que o poder havia sido apresentado e imposto conforme o direito, é dizer, em forma previamente já especificada. Essa fusão de ambos os aspectos do poder em domínio era indispensável, porque existia tão somente a jurisdição como administração local.

Essas considerações ensejaram, já na segunda metade do século XVI, um controle político centralizado da jurisdição, ao que por derradeiro anulou as demais jurisdições, tais como: jurisdição feudal, eclesiásticas ou corporativas, vez que essas jurisdições, via de regra, utilizaram seu próprio direito. O sentido desse controle 
político da jurisdição, visou, além de suprimir as complexidades e inseguranças jurídicas, também, suprimir a colisão entre os sistemas. Havia sim os simples sistemas sociais e o sistema político, entre a sociedade e o Estado.Se a primeira é constituída por indivíduos, já o sistema político impõe a existência de cidadãos,de um direito público e de uma ação de governo,que levariam o Estado a destacar-se da restante comunidade social, ou seja, o Estado assumiria a administração não só política mas também a administração jurídica.

Luhmann (2003, p. 294) enfatiza que a razão fundamental para que se consolidasse a fusão entre o direito e a política, deveu-se, sobretudo, pelo fato do problema do direito ser um problema de oposição. Esse problema foi algo constatado na Europa por um período aproximadamente de 100 anos de guerra civil. A ideia consistia basicamente o direito por si mesmo, por seus próprios recursos provenientes de uma tradição assentada num direito não escrito, estava pautado sob uma razão artificial do juristas e com uma fundamentação pessoal elaborada por aquele que via, e interpretava o direito à sua maneira pessoal, consequentemente, esse direito não garantia a paz. Toda essa estreita relação com a previa situação sócio estrutural era permeada por insegurança, duvidas e temeridades visto que as comunicações do sistema político baseavam-se sobre o poder. A nobreza baseava-se em seu próprio juízo acerca da justiça para justificar seus atos sobre a base de um governo próprio. Isso se deu não em menor grau àquelas práxis de ramificações do pensamento medieval que não se separava estritamente entre a religião, o direito e a moral. Essa integração, dentro de um mesmo contexto de interpretação ocasionava uma concatenação de conceitos que se unificavam, algo como uma espécie de simbiose, questões/argumentos teológicos e oriundos da moral convertiam-se em questões jurídicas passando a ser analisadas, doravante, no campo jurídico.

Daí surge uma nova leitura que descreve as práticas adversas e corruptas como práticas inconstitucionais. E por que isso? Os argumentos migram da esfera dos interesses econômicos da propriedade, ao que, agora o governo quando não representa e nem mesmo protege esses interesses, que constituem o fundamento da sociedade, deve contar/sofrer com uma oposição justificada. Assim, toda argumentação deverá se apoiar sob os parâmetros da virtude - versos - corrupção. Com isso, teremos então, pretensões de clausulas, versos, pretensões de clausulas do direito/jurídicas. Essas análises nos fornecem condições para se chegar a uma real/nítida compreensão daquilo que se entende por Direito e Liberdade. Dá relação entre política e direito logrou-se a compreensão daquilo que passou-se a compreender como Estado de Direito. Com o denominado Estado de Direito, o Estado assumiu - simultaneamente - duas faces que, doravante, o identificou: instituição de direito e instituição de responsabilidade política, olhando, observando e direcionando para o direito. Luhmann (2003, p. 298) fala de uma possível divergência - patologias políticas e patologias jurídicas - que adentra nas formas de inclusão dos cidadãos nos contextos jurídicos e políticos. Essas divergências se desprendem de contextos gerais e específicos de cada um dos sistemas. Essa controversas decorrem das formas de direito para influir politicamente 
sobre o próprio direito, e também, a proteção jurídica do cidadão contra o poder soberano, independentemente da práxis política adotada. Daqui surge antão uma concepção da democratização da política que exige, todavia, mais proteção legal ao particular, em especial, aquilo que concerne seus direitos constitucionais.

O conceito de Estado de Direito no pensamento de Luhmann não deriva da fusão dos dois sistemas: direito/jurídico - versos - político. O Estado de Direito deriva da atuação/funcionalidade dos dois sistemas diversos, cada qual com suas clausulas e suas operações, suas respectivas formas/sistemas, respectivas codificações e respectivos programas.

\section{O DIREITO}

A forma como o direito, ou, a ciência do direito/jurídica é abordada na teoria luhmanniana, demanda específico raciocínio lógico extraído de uma análise anatômica do próprio sistema que constitui a realidade própria da ciência do direito. A proposta formatada por Luhmann não se pauta pelo viés tradicional recorrente à consciência humana tomando-a como guardiã ou provedora do saber. Nos moldes da teoria de Luhmann, a consciência apenas aprender as verdades provenientes/inerentes do objeto, ou seja, as verdades aprendidas elas (ou ela), se constituem por si só, existem e estão presentes no próprio objeto. Dada concepção sistémicoteorético da autopoiese, a auto referência pertence à realidade una do direito como um sistema dentre os demais sistemas que integram a totalidade dos sistema-social. O conceito de auto referência não é mais compreendido como aquele estante na consciência humana ou no sujeito pensante, doravante é compreendido como aquele inerente ao domínio do objeto em si, a saber, para os sistemas reais como objeto da ciência. Para Neves (1994, p. 124),

Dai resulta uma certa distância em relação às dificuldades puramente lógicas da auto referência. Neste contexto não é mais o pensamento sobre o direito que é considerado como auto referencialmente constituído, mas sim, o próprio direito. A auto referência autopoiética não é, então, um problema a ser superado, mas sim condição imprescindível à unidade operacional e estrutural do sistema jurídico.

A concepção luhmanniana do direito vê e define o direito numa perspectiva empírica que se constitui mediante um sistema autopoiético fechado em si mesmo. O conceito de autopoiese surgi a partir da teoria biológoca elaborada por Maturana e Varela (NEVES, 1994, p 113). De origem grega o termo autós (por si mesmo) e poiesis (criação, engenho, produção) nos leva à compreensão que o respectivo sistema é construído por si só, pelos componentes que o integram e constituem sua própria anatomia. Neste sentido a autopoiese seria a composição/constituição do próprio sistema (vivo) como sistema que se reconstitui e instado numa rede de processo de produção, proporciona, contínua transformação e destruição de componentes, donde, mediante suas interações e transformações regeneram e realizam continuamente essa mesma rede de processo constituindo-a 
concretamente no espaço e especificando-lhe o domínio topológico. Neves, citando Matura e Varela, destaca o caráter homeostático desse sistema, onde se verifica um fechamento-em-si na produção e reprodução dos seus próprios elementos constitutivos (NEVES, 1994, p. 113). Com isso, rompe-se a velha tradição segundo qual a conservação e a evolução da espécie estariam condicionadas basicamente pelos fatores ambientais externos ao objeto.

Aqui o sistema da autopoiese distanciando da velha tradição se afirma como um sistema que se conserva e que vincula sua capacidade de reprodução autopoiética diferenciando-o num espaço determinado. Para Guerra Filho (2001, p. 182),

O sistema autopoiético é aquele dotado de organização autopoiética, em que há a (re) produção dos elementos de que se compõem o sistema e que geram sua organização pela relação reiterativa ("recursiva") entre eles. O sistema é autônomo porque o que nele se passa não é determinado por nenhum componente do ambiente mas sim por sua própria organização, isto, é, pelo relacionamento entre seus elementos.

A concepção Luhmanniana da autopoiese, até certo sentido, se distancia do modelo proposto por Maturana. Com esse distanciamento Luhmann pretendeu demonstrar haver certa distinção elementar que influenciaria, sobremodo, os sistemas constituintes do sentido (psíquico e social) do sistemas orgânicos e neurofisiológicos. Em se tratando dos sistemas constituinte de sentido a auto-observação constitui elemento fundamental à reprodução autopoiética, ao que de certo modo, destoa da compreensão dada pela teoria biológica da autopoiési que em si mesma é extremamente fechada obstruindo a possibilidade de reprodução das relações entre sistema e o meio ambiente, reprodução essa que demandaria um observador de fora, ou seja, um outro sistema. Os sistemas auopoiético de sentido demandam essencial auto-observação sem a qual não se poderá pensar a mínima possibilidade duma reprodução autopoiética.

Da auto-observação decorre a operação autopoiética num simultâneo processo de referência que se referenciam entre si - para dentro - e ao seu entorno/meio ambiente - para fora. Aqui, se compreende e chega-se as relações de sentido, no qual o processo em si não é prejudicado considerando-se que sentido só se relaciona com sentido e só pode ser alterado com sentido. A incorporação da diferença - sistema/meio-ambiente - no interior dos sistemas baseados no sentido possibilita uma combinação de fechamento operacional com abertura para o meio ambiente, de tal modo que a circularidade da autopoiese pode ter seu processo interrompido através da referência ao meio ambiente. Neves (1994, p. 114-115) realça que na teoria dos sistemas sociais autopoiético,

o meio ambiente não atua perante o sistema nem meramente como "condição infra-estrural da possibilidade da constituição dos elementos", nem apenas como perturbação, barulho. "bruit", constitui algo mais, "o fundamento do sistema". Em relação ao sistema atuam as mais diversas determinações do meio ambiente, mas elas só são inseridas no sistema quando esse, de acordo com seus próprios critérios e código-diferença, atribui-lhes sua forma.

Consoante análise, Guerra Filho (1997, p. 64) ressalta que doravante faz-se necessário chamar atenção para o "paralelismo" que se verifica entre o direito e a ciência, "ambos voltados para o desenvolvimento de 
segurança e estabilidade no sistema social global", visto que possibilitam fornecer garantias de expectativas com a denominada dupla seletividade onde temos a condição de deliberarmos quanto as possíveis seleções a serem tomadas fronte as diversas seleções possíveis do modo que se agirá. Guerra Filho, com sua brilhante maestria, segue nos apontando certa diferença que entremeiam as expectativas normativas - garantidas pelo direito - e as expectativas cognitivas - garantidas pela ciência - vez que essas, ao se perceberem frustradas pelas contingencias, "devem procurar se adaptar aos fatos que as frustram, enquanto as primeiras, ao contrário, são concebidas para se manterem "contrafaticamente", isto é, "mesmo depois de frustradas".

A pergunta acerca da função do direito é elaborada sempre voltada ao sistema da sociedade, ou melhor, a preocupação de fundo desta pergunta busca resolver/solucionar patologias do sistema social como um todo, assim, normas especificamente jurídicas oriundas dum sistema jurídico específico é a condição determinante para soluções dessas contingencias. Aqui a ciência do direito se depara com uma tarefa muito árdua que lida especificamente com aquelas problemáticas oriundas de afirmações, consciência e modo de ser dos indivíduos. Por outro lado, temos a sociedade como um sistema unitário que também pode ser observado empiricamente já que se apresenta de modo concreto com suas comunicações habituais altamente complexas. Por isso mesmo, aponta Luhmann (2003, p. 85), há que se buscar afirmações que se pode generalizar recorrendo aos possíveis sistemas existentes (diversos). Aqui parece estarmos tratando duma abstração do direito quando nos referimos a função do direito que se orienta e se expressa atrelado as expectativas contingências que se ampliam no tempo. A perspectiva abstrata do direito não é tomada enão nos leva a afirmar/dizer que o direito estará desincumbido do deve de observar e sentir as contingências sociais que se desprendem dos enlaçamentos do tempo que suscitam expectativas, pelo contrário, quando colocamos em pauta a função do direito pretende-se com isso abordar possibilidades de estabilização das expectativas através de regulação e generalização temporal, objetivo da sociedade. A estabilização de expectativas demanda uma seguridade que irá conferir aos indivíduos condições para enfrentar/lidar a desordem, abalos e demais patologias da vida social/cotidiana como um todo; assim, pessoas e grupos não estarão mais desacreditados em relação as suas expectativas.

Uma das observações mais importantes que lida especificamente com os pressupostos da função da norma a qual nos orienta a respeito da função própria do direito, direciona nossas observações a denominada diferenciação entre o direito e a política e aqui fala-se numa dependência mútua entre esses dois sistemas. Em El Derecho de laSociedad, Luhmann (2005, p. 106) aponta que para sua aplicação o direito depende da política, de modo que, sem a perspectiva dessa "imposição" não existe nenhuma estabilidade normativa convincente que possa ser atribuída a todos. A política, por sua vez, recorre ao direito como condição para se obter o devido acesso ao poder politicamente concentrado. Contudo, não obstante mútua dependência, ambos sistemas são e atuam de modo diversos. A ordem pressuposta na suposta função do direito traz em si uma peculiaridade inquietante, a 
saber, o que se pode esperar justificadamente dos outros. A inseguridade a respeito das expectativas é mais insuportável do que suportar as más surpresas e descontentamentos não previsíveis. Aqui nos deparamos com uma questão há muito tempo já levantada pelo teóricos do direito ${ }^{3}$, que realça o problema da imposição jurídica. Não restrita tão-somente ao ponto de vista político, mas, sobretudo, do ponto de vista da moral, trata-se da questão de saber se uma ação pretendida/exigida pode ser imposta mediante coação, ou ainda, até que medida podemos dizer, ou afirmar, não ser impróprio para um homem exigir/determinar um comportamento de outrem? Esse tipo de análise figura-se como uma demanda preliminar necessária par a avaliação crítica tanto do direito como da moralidade popular/social sobre o qual o direito não está imune. Assim, enquanto não tivermos clareza sobre que juízo ou pratica moral o direito reflete, não poderemos criticá-lo inteligentemente. Contudo, quando essas questões se mostrarem resolvidas, restará ainda outra pergunta se essa prática é sensata, bem fundada e coerente com os demais princípios do direito (DWORKIN, 2007, p. 12). A observação de Luhmann (2005, p. 107) destaca que a sociologia jurídica que se apoia predominantemente no poder de sanção tem sua origem no século XVIII. Já nesta época havia uma distinção entre o direito como obrigação externa e a moral como obrigação interna, ambas incumbidas de reger os acordos e as expectativas primordialmente política. Considerando as bases de funções distintas da política e do direito Luhmann (2003, p. 109) fala se uma certa sínteses das funções:

Se a política lograra realmente seu objetivo de impor as decisões vinculantes para a comunidade de maneira efetiva e sem exceções, o sistema jurídico se encontraria em situação paradoxal: por u lado já não teria nenhum problema porque já não havia que contar com expectativas que se frustram, por outro lado, se sentiria decepcionado em suas próprias expectativas pela sua erupção em seu campo do sistema político. Dito de outra maneira, existem boas razões para que a imposição jurídica se limite ao necessário para que as expectativas resistam as decepções.

No contexto moderno os processos de engajamento das diferenças se realizam mediante o procedimento contencioso de tipo jurídico. Com isso temos a possibilidade da garantia legal que se mostra presente em cada momento possibilitando a forma de um eventual consenso na forma do direito vigente que abre, por sua vez, a possibilidade de denúncia. O procedimento de conciliação, pensado nos moldes da teoria de Luhmann, vive da função substancial do direito que consiste em estabilizar expectativas normativas. Com isso, as formas de conciliação no direito alcança uma segurança social que favorece os sistemas psíquicos e sociais que tenha sido afetados. Assim, se pretende avaliar tanto a função como as prestações do sistema jurídico em seu conjunto como um sistema imunológico, vez que o direito é visto como um sistema que imuniza a sociedade. Deste modo não pode haver espaço onde o direito não possa atuar, nem uma situação nas qual o direito não possa intervir, ou seja, nenhum enclave arbitrário ou violento. O direito, para se autoproduzir, não pode estar

\footnotetext{
${ }^{3}$ Ver: L.A. Hart. The Concepto of Law. R. Dworkin. Taking Rights Seriously.
} 
fechado às situações e ocorrências do seu contexto. Pensar um ordenamento jurídico não significa referenciarmos tão somente aglomerado de normas existentes, devemos referenciarmos também condutas que estabeleçam normas e, destaca Guerra Filho (2001, p. 190) "em sendo esse ordenamento autônomo, as condutas que estabelecem novas normas já são elas próprias reguladas por normas anteriores".

\section{CONCLUSÃO}

Dentro das perspectivas abordadas em linhas supra, ficou claro que o sistema social, em seu todo, é constituído com outros (sub) sistemas e assim a o sistema social é observado/tomado como uma entidade teórica que seria composta de interações pessoais, coletivas e grupais. Temos aqui algo como uma espécie de interdependência entre os sistemas, por exemplo, o sistema jurídico/direito e o sistema político. O sistema social significa o conjunto das redes de relações pelos quais dois ou mais atores estão em relação uns com os outros, se influenciam e são influenciados. Deste modo, tanto o sistema político, como o sistema jurídico - assim como os demais sistemas (econômico, religioso, antropológico etc.) passam a ser tomados como modos ou possibilidades que correspondem a uma maneira de perceber o real. As realidades que são observadas no interior da sociedade, via sistemas, se diferenciam, entretanto, elas mantem uma referência quanto a forma com que os meios de comunicação as observam, bem como a influência que eles têm sobre as estruturas do conhecimento diário, consoante senso comum e, também, a pressão que eles exercem sobre função de cada sistema.

As possibilidades, ainda que insuficientes, de uma observação interna e externa, não auxiliam muito perante uma situação fundamental. Em seu módulo operativo, os sistemas podem distinguir suas operações e, assim, num sentido autorreferencial o sistema pode comunicar a diferença entre sistema e meio. Portanto, chegase a compreensão concernente a problematizada questão da capacidade de sobrevivência da sociedade moderna diante dos múltiplos problemas que não se restringe a locais específicos ou espaços geográficos determináveis, antes sim, fronte aos problemas que transpassaram fronteiras e alcançaram regiões longínquas com dimensões globais, problemas de ordem ecológicas, humanitárias, direito de cidadania e etc., em outra palavras, da possibilidade de reprodução dos acoplamentos negativos do sistema fronte ao meio; paralelamente, coloca-se, no mesmo nível, o acoplamento negativo da sociedade perante o ser humano/indivíduo, que na sociedade moderna, e apreendido como indivíduo, isto é, como um solipsista, um auto-observador. 


\title{
POLITICS, POWER AND LAW: REFLECTIONS AND FRAGMENTS OF LUHMANN'S THOUGHT
}

\begin{abstract}
Analyzing aspectsof power as forms of domination and its relation to politics and Law is the object of this article. In this sense, our article anticipates its reflections raising beforehand some questions, such as: would there be any sense to think about a coexistence between power, politics and law? The existence / permanence of the right would be compromised divorced from a coexistence of power? Taking as a theoretical reference the work of Niklas Luhmann our article Will direct his analysis to the systemic conception of Law and politics, linking to the concept of Power addressed in Luhmann's thought.
\end{abstract}

Keywords: Power. Polict. Right. System. Communication.

\section{REFERENCIAS}

DWORKIN, Ronald. Levando o direito a sério. Trad. Jefferson Luiz Camargo. São Paulo: Martins Fontes, 2007.

FERRAZ JUNIOR, Tercio Sampaio. Estudos de Filosofia do Direito. 3a Ed. São Paulo: Atlas, 2009.

GUERRA FILHO, Willis Santiago. Teoria da Ciência Jurídica. São Paulo: Saraiva, 1997.

Autopoiese do Direito na Sociedade Pós-Moderna. Porto Alegre: Livraria do ADVOGADO, 2001.

LUHMANN, Niklas. Introdução à Teoria dos Sistemas. Trad. Ana Cristina Arantes Nasser. 2a Ed. Petrópolis: Vozes, 2010.

LUHMANN, Niklas. EL DERECHO DE LA SOCIEDAD. Trad.Javier Nafarrate Torres, México: UniversidadIberoamericana, 2005.

Poder. Trad. Martine Creusot de Rezende Martins. Brasilia: Universidade de Brasilia, 1985. 
NEVES, Marcelo. A CONSTITUCIONALIZAÇÃO SIMBÓLICA. São Paulo: Acadêmica, 1994.

STRAUSS, Claude Lévi. RAÇA E HISTÓRIA.Trad. Inácia Canelas. São Paulo. Abril S.A, 1976.

ROCHER, Guy. TalcottParsons e a Sociologia America. Trad. Olga Lopes da Cruz. Rio de Janeiro: Livraria Francisco Alves Editora S.A, 1976.

Trabalho enviado em 16 de janeiro de 2018

Aceito em 10 de junho de 2018 